REVISTA DE DERECHO UNED, núm. 1, 2006

\title{
SOBRE EL CARÁCTER CRÍTICO DE LA FILOSOFÍA DEL DERECHO
}

\author{
BENJAMÍN RIVAYA GARCía
}

Sumario: I.-II.-III.-IV.-V.-VI.-VII.-VIII.-IX.-

I.

El concepto, sentido y función de la filosofía del Derecho, como el de la filosofía en general, es problemático; al menos en la medida en que esas cuestiones pueden ser y de hecho son abordadas y resueltas de diversa manera, precisamente según cuál sea la filosofía que profese quien se las plantee. No puede producir extrañeza la simple constatación: escolásticos, marxistas y analíticos, entre otros, enfrentan planteamientos dispares al respecto, e incluso en ocasiones se niegan a considerar verdaderos filósofos a quienes sustentan posturas que no concuerdan con las suyas. Algunas de las polémicas más divertidas y profundas sobre lo que sea la filosofía, y la filosofía del Derecho, encierran posiciones que argumentan el repudio que sienten por algún tipo de pensamiento, a la vez que justifican el rechazo a admitir que sea verdaderamente filosófico. Por ejemplo, en España Manuel Sacristán vino a negar carácter científico a la filosofía a secas, a la vez que afirmó que los verdaderos filósofos no eran los que se tenían por tales'; y en los ámbitos de la filosofía del Derecho, Felipe González Vicén también aseguró que los iusnaturalistas no eran

1 Algunas de la tesis que mantuvo Manuel Sacristán en «Sobre el lugar de la filosofía en los estudios superiores" eran fuertes: "los sistemas filosóficos son pseudo-teorías, construcciones al servicio de motivaciones no teoréticas, insusceptibles de 
auténticos filósofos del Derecho². Aunque en sus escritos se adeudara mucho a las circunstancias españolas de fines de los sesenta (aparecieron publicados casi a la vez, en 1968 y 1969 respectivamente), ambos mostraban razonamientos propiamente filosóficos. Por eso cuando uno se adentra en esa particular literatura que se dedica a clarificar lo que sea la filosofía jurídica, no deja de causar estupor que, salvo excepciones, reine un asombroso consenso alrededor del carácter crítico que se le asigna. El término «crítica», además, se repite por casi todos con una insistencia que sorprende, aunque habitualmente no se sienta la necesidad de explicitar por qué ni qué se quiere decir. Ante el acuerdo reinante, las preguntas que cualquier curioso lector se hará, son obvias: ¿cómo puede ser que pensadores tan dispares, enfrentados en esenciales aspectos, digan lo mismo en este punto? ¿De veras todos quieren decir lo mismo cuando predican que la filosofía del Derecho, para serlo, ha de ser crítica? ¿Qué quiere decir crítica? ¿Quién está legitimado para afirmar que un pensamiento es crítico? Y si no lo es, ¿no es filosofía del Derecho? Pero entonces ¿qué es?

II.

Admitido que la filosofía jurídica española no constituye una excepción extraña en el panorama internacional sino que, al contrario, en ella se dan cita los tópicos filosóficos que también están extendidos por otras latitudes ${ }^{3}$, basten algunos ejemplos que sean repre-

contrastación empírica (o sea: indemostrables e irrefutables) y edificados mediante un uso impropio de los esquemas de la inferencia formal». No es extraño que Sacristán afirmara acto seguido que «todas las horas de lección magistral y de seminario de las secciones de filosofía y todas las publicaciones de sus magistri pesan infinitamente menos que un centenar de páginas de Einstein, Russell, Heisenberg, Gramsci, Althusser y Lévi-Strauss -o hasta de Galbraith o Garaudy (para que queda claro que esas enumeraciones no implican especial afecto del que escribe)—»; en "Sobre el lugar de la filosofía en los estudios superiores", Papeles de Filosofía. Panfletos y Materiales $I I$, Barcelona, Icaría, 1984 (pp. 356-380), pp. 357 y 360.

2 En efecto, porque a su juicio la filosofía del Derecho es una forma de reflexión sobre las leyes humanas, que renuncia "por principio a traspasar las fronteras de lo dado históricamente en el campo del Derecho"; en "La filosofía del Derecho como concepto históricon, Estudios de Filosofía del Derecho, La Laguna, Facultad de Derecho de la Universidad de La Laguna, 1979 (207-257), p. 256. Un estudio sobre la referida tesis de González Vicén, en Benjamín RIVAYA, «La filosofía del Derecho como concepto formal (Sobre la filosofía jurídica española de los años sesenta)», Boletín de la Facultad de Derecho de la UNED 13, 1998 (pp. 15-48).

${ }_{3}$ No se puede obviar el dato de que una de las teorías más de moda, la de la escuela de Frankfurt, se autodenomina precisamente crítica. En Habermas se ve clara la 
sentativos en nuestro país para probar que hoy en día se cree que la iusfilosofía tiene o ha de tener un carácter crítico.

En el número tan comentado que los Análes de la Cátedra Francisco Suárez dedicó a lo que fuera la filosofía del Derecho, pero también en el primer número de la revista Doxa, y en muy variados artículos y libros, una cantidad considerable de profesores españoles de la disciplina, señaló el sentido, función o carácter crítico que le correspondía al saber al que se dedicaban ${ }^{4}$. Creo que en nuestro ámbito geográfico ha sido Elías Díaz uno de quienes más ha resaltado esa característica que le ha de corresponder a la filosofía del Derecho. En su Sociología y filosofía del Derecho, cuya primera edición apareció en 1971, ya señalaba que este saber se constituía por la ontología jurídica, "totalización y comprensión trascendental crítica de los resultados de la Ciencia y la Sociología del Derecho", la teoría de la ciencia jurídica, «reflexión crítica sobre la Ciencia del Derecho y sobre la actividad científica propia de los juristas", y la axiología jurídica, «enjuiciamiento crítico del Derecho positivo desde un determinado sistema de valores $»^{5}$.

Publicado también en los Anales de la Cátedra Francisco Suárez, otro trabajo de especial importancia para nuestros propósitos fue el firmado precisamente por tres discípulos de Elías Díaz, por Laporta, Hierro y Zapatero. Literalmente: «La Filosofía del Derecho no se justifica solamente por una especie de pluriempleo. No se justifica porque haya una serie de importantes, necesarias y urgentes materias que nadie quiere o nadie sabe acometer. La Filosofía del Derecho no adquiere sentido y función sólo por que la Teoría General del Dere-

identificación entre filosofía, racionalidad y crítica: «Philosophy as Stand-In and Interpreter», en Kenneth BAYNES, James BOHMAN y Thomas MaCARTHY, After Philosophy. End or Transformation?, USA, The Mit Press, 1989 (488 p.), p. 312. Pero también otros filósofos contemporáneos de renombre suelen apelar, aun de diferentes formas, a la crítica: vid. el citado libro de BAYNES, BOHMAN y McCARTHY, pp. 4-6.

"Vid. Benjamín RIVAYA, "La filosofia del diritto in Spagna", Materiali per una Storia della Cultura Giuridica XXXI, 1, 2001 (pp. 263-278).

5 Elías DIAZ, Sociología y Filosofía del Derecho, Madrid, Taurus, 1974 (449 p.), pp. 265-266. Después, en el artículo suyo que apareció en los Anales, volvió a recalcarlo: la filosofía del Derecho se constituía por una teoría crítica del Derecho, una teoría crítica de la ciencia jurídica y una teoría crítica de la justicia. «En mi opinión es, pues - dijo-, esa fundamental tarea crítica la que, en esos tres niveles, precisamente configura y define el «sentido y función de la Filosofía del Derecho en la actualidad»; en «Legitimidad crítica y pluralismo ideológico», Anales de la Cátedra Francisco Suárez, 1975 (pp. 45-63), p. 50. Más tarde Elías Díaz volvió a resaltar ese aspecto crítico de la filosofía del Derecho, que sería "un importante capítulo de esa filosofía de la praxis, de esa filosofía ética que trata de valorar críticamente la realidad»; en Curso de Filosofía del Derecho, Madrid, Marcial Pons, 1998 (205 p.), p. 185. 
cho, o la Sociología, o cualquier otro sector sean materias necesarias, imprescindibles para la formación realmente universitaria del jurista. Ni mucho menos se justifica la Filosofía del Derecho por la necesidad de dar una «culturilla» filosófica al jurista [...] La Filosofía tienen fundamentalmente una función y se justificará de hecho si la cumple: se trata de la crítica». Eso no quiere decir, advierten, que privilegien el momento práctico de la filosofía a costa del teórico; en absoluto, pues la crítica requiere herramientas, y éstas son los valores. Así, a su entender, la filosofía del Derecho parece ser, sobre todo, teoría del conocimiento de los valores ${ }^{6}$.

También Manuel Atienza afirmó el sentido crítico que había de tener la filosofía jurídica: quienes habían pregonado «la muerte de la filosofía», quizás sin quererlo, le habían prestado un magnífico servicio a ésta - decía-, el de pulverizar las filosofías tradicionales, a la vez que posibilitado el «establecimiento de una nueva actitud filosófica, antidogmática y crítica». Además resaltó que esta nueva actitud se plasmaría en una nueva filosofía que, a su juicio, «debería construirse como crítica al "Derecho Natural», esto es, contra "cualquier concepción metafísica del Derecho", y luego aclaró que por tal entendía «la pretensión de decir lo que sea lo jurídico o lo justo de una vez para todas, de fundamentar el Derecho en la idea de un orden eterno e inmutable, etc., etc.» ${ }^{7}$. Que yo sepa, en otra ocasión se ocupó Manuel Atienza con el asunto, cuando apuntó las notas características que le correspondían a la filosofía jurídica: saber totalizador, crítico, práctico y útil, dijo. Pero no especificó en qué habría de consistir la crítica, sino que simplemente dijo que habría de ejercerse desde una perspectiva que no coincidiera con la de quienes se colocaban en el interior de cada una de las parcelas del Derecho, con lo que el filósofo del Derecho lo que debía era cuestionar los límites establecidos, lo que no podría hacer quien se dedicara a una concreta ciencia o técnica ${ }^{8}$. En El sentido del Derecho lo clarificó más: la filosofía jurídica ha de cumplir una misión crítica en tanto que supervisora de los conceptos y métodos usados por los juristas. Acto seguido añadió que también debía cumplir otra función de orientación práctica (a la que no llamó crí-

6 Francisco J. LAPORTA, Liborio L. HIERRO y Virgilio ZAPATERO, «Algunas observaciones sobre la situación de la filosofía del Derecho en la actualidad", Anales de la Cátedra Francisco Suárez, 1975 (pp. 93-120), pp. 118-119.

7 Manuel ATIENZA, «Ontología del Derecho versus metafísica del Derecho», Anales de la Cátedra Francisco Suárez, 1975 (pp. 1-10), pp. 2-4.

8 Manuel ATIENZA, Introducción al Derecho, Barcelona, Barcanova, 1985 (403 p.), pp. 371-372. 
tica, pero podría haberlo hecho), la de enseñar «lo que no debe ser el Derecho" ni los saberes jurídicos".

Pero quizás ha sido Juan Ramón Capella quien resaltara aún más el carácter crítico del conocimiento filosófico jurídico, además de que a su propia producción doctrinal se la denomine crítica o se la ponga en relación con las ideologías críticas. «En España — dice Juan A. Pérez Lledó- no existe una corriente crítica, aunque se debe destacar la obra, un tanto aislada, de Juan Ramón Capella» ${ }^{10}$. Además de sus contribuciones a la filosofía del lenguaje, creo que Capella se ha significado en el panorama español por la defensa del marxismo jurídi$c o$, aunque peculiar, con rasgos propios. Por lo que ahora interesa, un libro suyo que se publicó en 1976 llevó por título precisamente Materiales para la crítica de la filosofía del Estado, y en él se contenían diversos trabajos publicados anteriormente. En uno de ellos, Sobre la extinción del Derecho y la supresión de los juristas, un opúsculo que ya había aparecido en 1970, Capella hablaba de los «sanos martillazos de la crítica ${ }^{11}$, y se evidenciaba a quiénes se les daban esos martillazos: al Derecho tradicional, a la teoría del Derecho tradicional, a la pedagogía tradicional y a la práctica jurídica tradicional. No es extraño que a su filosofía jurídica se la tenga por crítica. Conforme a lo que luego repetiría, su forma de concebir la iusfilosofía ya no deja lugar a dudas: «la filosofía del derecho y del estado es, necesariamente, crítica del poder establecido - sea cual sea la naturaleza de este poder-o bien su cómplice. Sin términos medios» ${ }^{12}$.

En una línea que creo similar, Xacobe Bastida argumentó en El Derecho como creencia (un libro, por desgracia, poco conocido en España) a favor del carácter crítico de la filosofía jurídica. Dijo que era un lugar común hablar de la dimensión crítica de la filosofía del Derecho y expuso, como hago yo ahora, diversas opiniones que lo avalaban. Luego arremetió: la filosofía debe «[e]xtirpar la creencia en

9 Manuel ATIENZA, El sentido del Derecho, Barcelona, Ariel, 2003 (336 p.), p. 249.

10 Juan A. PÉREZ LLEDÓ, «Teorías críticas del Derecho», en Ernesto Garzón Valdés y Francisco J. Laporta, El Derecho y la justicia II. Enciclopedia Iberoamericana de Filosofía, Madrid, Trotta, CSIC y BOE, 1996 (pp. 87-102), p. 93.

11 Juan Ramón CAPELLA, Materiales para una crítica de la filosofía del Estado, Barcelona, Fontanella, 1976 (211 p.), p. 46. Posteriormente, en el breve artículo que publicó en el monográfico que los Anales de la Cátedra Francisco Suárez dedicaron al concepto de la filosofía del Derecho, se evidenció otra vez el carácter crítico de su filosofar: ni positivismo ni iusnaturalismo, lo que había que hacer era cambiar de "sistema»; en "Sobre las perspectivas de la filosofía del Derecho», Anales de la Cátedra Francisco Suárez, 1975, p. 24.

12 Juan Ramón CAPELLA, «Presentación» al libro de Carlos María Cárcova, La opacidad del Derecho, Madrid, Trotta, 1998 (pp. 9-12), pp. 9-10. 
las cosas que parecen más seguras» y «casi con toda probabilidad dijo-, la reflexión filosófica acerca del Derecho surgió con el primera desobediente ${ }^{13}$. Dada la concepción del Derecho que expone, precisamente una creencia en el sentido orteguiano del término, su filosofía del Derecho resulta subversiva, rompedora, revolucionaria. Por lo demás, como no podía ser de otra forma, aseguró que el conocimiento iusfilosófico habría de ser un conocimiento de tipo etic, desde afuera, diríamos, y que, aunque sea necesario tenerlo en cuenta, en último término excluye el conocimiento emic, desde dentro ${ }^{14}$.

Desde otra perspectiva Pérez Luño también ha solido resaltar el carácter crítico que le ha de corresponder a una filosofía del Derecho correctamente orientada. Precisamente ésta «aparece desde que los hombres comienzan a cuestionarse y cuestionar racionalmente el sentido y el valor de las reglas sociales de comportamiento que a lo largo de la historia han venido a organizar su convivencia», lo que es lo mismo que decir que tiene por misión criticar la organización de la vida social y, a la vez, "suministrar criterios para orientar la acción», para organizarla, y todo ello en el marco de un «horizonte utópico situado en la lucha por la sociedad justa que garantice el pleno desarrollo de la persona en una comunidad definitivamente desalienada», con lo que Pérez Luño no sólo emplaza a la filosofía del Derecho para la crítica, sino que ofrece los criterios que ha de manejar ${ }^{15}$.

Precisamente esta cuestión tiene especial importancia, y así lo resaltó Gil Cremades, quien también defendió una concepción "crítica" de la filosofía jurídica, si bien advirtió que esa defensa no debía significar la prédica de ninguna "fe utópica». Pero por lo que ahora interesa, criticar - dijo- es imposible si no se tienen criterios, lo que es obvio pero a veces, incluso a menudo, se olvida. Pero la exposición de Gil Cremades sirvió para ahondar más en la cuestión: la filosofía del Derecho habría de ser provocativa o, lo que es lo mismo, crítica «ante una situación establecida», según que atienda más o menos "al proceso emancipatorio del hombre». Además, habría que distinguir entre lo que se puede y lo que se debe criticar, y una vez establecido el objetivo, llevar a cabo desinteresadamente la labor. Una advertencia, a la hora de ejercer la crítica filosófica se deben respetar los principios procesales del razonamiento y la discusión. La carga de la prueba corres-

13 Xacobe BASTIDA, El Derecho como creencia. Una concepción de la filosofía del Derecho, Bogotá, Universidad Externado de Colombia, 2000 (303 p.), pp. 223-226.

14 Xacobe BASTIDA, El Derecho como creencia, cit., pp. 172-173.

15 Antonio Enrique PÉREZ LUÑO, Lecciones de Filosofía del Derecho. Presupuestos para una teoria de la experiencia jurídica, Sevilla, Universidad de Sevilla, 1982 (147 p.), pp. 111-113. 
ponde al que critica: «La validez de lo existente no se eleva a dogma, pero está protegido por aquellas reglas conforme a las que se reparte la obligación de probar y fundamentar. La negación de lo antiguo y la afirmación de lo moderno han de hacerse conforme a reglas». Pero si antes decía que Gil Cremades apuntaba a la emancipación humana como criterio para la crítica, ahora he de decir que ese objetivo conecta con el de la rehabilitación de la razón práctica que propone: porque poseemos «un conocimiento depurado de medios, cuyo empleo se deja, en cambio, en manos de potencias irracionales, que determinarán mediante decisiones imparticipables e irrebatibles -en cuanto subjetivas- los fines a conseguir aquí y ahora». Así, parece que es cosa de la filosofía jurídica el fin de hacer vislumbrar los fines ${ }^{16}$. Pero de Gil Cremades interesa otra cuestión, pues ejemplifica un dato: que reconocer la función crítica que asume este tipo de saber no significa necesariamente menosprecio ni condena del Derecho, pues éste o, en otros términos, «la razón jurídica, ha sido, con mayor o menor alcance, un instrumento racionalizador del ejercicio de la autoridad ${ }^{17}$.

Los ejemplos citados ya serían suficientes para apuntar el tópico, pero podríamos señalar muchos otros: Gregorio Peces Barba dijo que era la dimensión crítica la que justificaba la filosofía jurídica, dimensión que se veía inmediatamente en la teoría del Derecho justo ${ }^{18}$; Eusebio Fernández aseguró que la Filosofía del Derecho podía y debía ser teoría crítica del Derecho, ésta es, la que se cuestiona, "desde perspectivas éticas, políticas y sociales, los principios que inspiran, los fines que se quieren conseguir y las funciones que realmente se cumplen con la existencia de un determinado ordenamiento jurídico» ${ }^{19}$; para Nicolás María López Calera, la iusfilosofía cumple dos funciones, la crítica («para decir al Derecho existente lo que no debe ser») y la utópica (para decirle «lo que debe ser») ${ }^{20}$; para Prieto Sanchís, la filosofía del Derecho se justifica por ser «estímulo y conciencia crítica del Derecho y del saber dogmático» ${ }^{21}$. Podríamos seguir señalando ejemplos, pero ya es suficiente.

16 Juan José GIL CREMADES, «Un futuro posible de la filosofía del Derecho», Anales de la Cátedra Francisco Suárez, 1975 (pp. 65-81), pp. 70-80.

17 Juan José GIL CREMADES, «Razón práctica y razón jurídica», Anales de la Cátedra Francisco Suárez, 1977 (pp. 1-24), p. 24.

18 Gregorio PECES BARBA, Introducción a la Filosofía del Derecho, Madrid, Debate, 1983 (370 p.), p. 190. p. 20 .

19 Eusebio FERNÁNDEZ, Estudios de ética jurídica, Madrid, Debate, 1990 (154 p.),

${ }^{20}$ Nicolás María LÓPEZ CALERA, Filosofía del Derecho (I), Granada, Comares, 1997 (278 p.), p. 35.

21 Luis PRIETO SANCHÍs, "Un punto de vista sobre la Filosofía del Derecho", Anuario de Filosofía del Derecho VI, 1987 (pp. 591-617), p. 592. 
III.

Con las noticias ofrecidas, y supuesto que puedan ser generalizadas, creo que se puede decir que un tópico que se repite al hablar hoy día de la filosofía del Derecho, es el de su carácter crítico. Aunque quizás el término se haya repetido menos en un pasado no lejano ${ }^{22}$, incluso aunque haya autores contemporáneos que no suelan utilizarlo, me parece que lo que con él se intuye es una tesis muy generalizada, aunque pocas veces se haga explícita, precisamente porque se presume que es fácilmente comprensible. ¿Realmente lo es? Por otra parte, se trata de una palabra típicamente filosófica, que no siempre se ha utilizado en el mismo sentido, sino con significados, matices y sesgos diversos. Quien quiera adentrarse en ella, entonces, habrá de preguntarse en qué consiste criticar, sabiendo de antemano que puede no consistir siempre en lo mismo.

Etimológicamente, el término crítica proviene del griego крı пико (capaz de juzgar), que reenvía al de kpıбı (separación, elección, disputa, juicio, sentencia, condena, resultado, crisis, acusación, proceso,

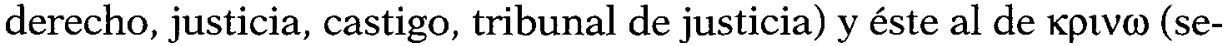
parar, preferir, acusar, juzgar, interpretar, condenar). Así, resulta que el filósofo del Derecho, a veces sin darse cuenta de ello, utiliza una voz que está muy vinculada a su objeto. En fin, aunque alguno de los sentidos etimológicos nos resulten particularmente interesantes, hoy la palabra crítica suele presentar la ambivalencia de dos significados ligados entre sí por la relación entre el todo y la parte: el juicio y la condena. Incluso incluyendo el de "murmuración", los significados existentes se pueden reducir a dos: crítica es el juicio sobre algún valor de las cosas, tanto como la censura por carecer de él.

Por lo demás, se trata de un término de uso común, no sólo en el lenguaje mundano sino también en ciertos ámbitos del saber. Así, en nuestros días se puede oír hablar de edad crítica, conciencia crítica, crítica literaria, crítica cinematográfica, crítica bíblica, crítica de libros, ensayos críticos, estudios críticos, introducciones críticas, biografías críticas, bibliografías críticas, ediciones criticas; y en el ámbito

${ }^{22}$ Por ejemplo en los Archives de Philosophie du Droit de 1962, que se dedicaron casi monográficamente, en extenso, a tratar la cuestión de lo que fuera la filosofía jurídica, se podía ver utilizado el término "crítica», si bien en menor medida que en la bibliografía española analizada, aunque también, al igual que aquí, el término se usó con distintos sesgos: por ejemplo, p. 90 (Bagolini), 94 (Battiffol), 120 (Gardies), 155 (Treves). En cuanto a algunos filósofos del Derecho de especial renombre, caso de Legaz y de Recaséns en España, es curioso que no solieran utilizarlo en relación con la filosofía del Derecho. 
de las ciencias sociales no es infrecuente la utilización de expresiones como teoría crítica, metodología crítica, investigación crítica, historia crítica, sociología crítica, economía crítica, pedagogía o educación crítica. Incluso en el ámbito del Derecho tampoco es raro que se use el término en referencia a una concreta rama de la Jurisprudencia (recuérdese en nuestro país la clásica Revista crítica de Derecho Inmobiliario), a una teoría jurídica, o a un sector del conocimiento que guarda estrecho contacto con el jurídico, como la criminología, muchas veces adjetivada como crítica.

Por lo que hace a la filosofía, y a la filosofía del Derecho también, lo más probable es que a quien se identifique con el uso del término sea a Kant, padre del criticismo, sin duda por el uso que le daba, que se plasma en el título de algunas de sus principales obras: la Crítica de la Razón Pura, la Crítica de la Razón Práctica o la Crítica del Juicio. Pero en la especulación kantiana la palabra cobra un entendimiento distinto del que se le suele dar en el uso corriente: con sus postulados, critica es la investigación que se ocupa con la posibilidad y los límites del conocimiento, posibilidad y límites que requieren ciertas categorías a prio$r i$, esto es, que crítica es la investigación de esos conceptos a priori que hacen posible el conocimiento. En la estela del kantismo, después lo utilizarían otros muchos con ese mismo sesgo epistemológico.

Pero la tradición respecto al uso del término, sufrirá un giro espectacular frente a ese empleo, y también se radicalizará, en las obras de Marx y de Engels, quienes lo repetirán una y otra vez. Repárese en algunos de los títulos de sus trabajos más conocidos: además de la Crítica de la filosofía del Derecho, de Hegel, de la Crítica del programa de Gotha, de la Crítica de la división del trabajo, o de la Historia critica de la plusvalía, El Capital llevó por subtítulo Crítica de la economía política, La ideología alemana, crítica de la novísima filosofía alemana, y La Sagrada Familia se subtituló, aunque fuera con sorna, así, Crítica de la crítica crítica contra Bruno Bauer y consortes, nada menos. Me parece que en las plumas de Marx y de Engels, a las claras, la palabra adquiría un significado revolucionario, subversivo; y si bien es cierto que se puede defender que la filosofía kantiana también era revolucionaria, desde luego no lo era en el mismo sentido en que lo era la de Marx y los marxistas, directamente político en este caso. Tampoco deja de ser verdad que la palabra se podía entender como ataque a la fundamentación de cierta doctrina (la del Derecho, de Hegel, por ejemplo), pero tras esa ofensiva primera se escondía la lucha política contra el status quo ${ }^{23}$.

${ }^{23}$ Para ilustrar estas referencias a las dos grandes corrientes críticas, conviene traer a colación el estudio de Bottomore sobre la crítica social, para quien fueron los en 
En los ámbitos de la filosofía del Derecho, más cerca de nuestro tiempo, ambas direcciones hallaron plasmación: la idealista, en el resurgimiento del kantismo que se produjo a fines del siglo XIX y principios del xx; la materialista, en varias teorías sobre el fenómeno jurídico que, en diversa medida, se inspiraron en el marxismo y que ocupan, hasta nuestros días, todo el siglo Xx. Las primeras fueron denominadas teorías neocríticas, y las segundas, aun con variantes, se suelen denominar teorias críticas del Derecho. Por lo que hace a los neokantianos, probablemente fuera Stammler su más significado representante: su teoría —dijo- era crítica, con lo que quería dar a entender que seguía el método crítico, un método que partía de distinguir entre los elementos contingentes de cada Derecho y los comunes a todos ellos, constituyendo estos últimos, que se hallarían por medio de la «introspección crítica», su objeto ${ }^{24}$. La crítica neokantiana enlazaba con la etimología de la palabra, pues se trataba de ordenar (separar, discriminar) los materiales jurídicos, de tal suerte que pudieran ser conocidos científicamente.

En cuanto a los neomarxistas y otros pensadores de izquierdas que, asumiendo en todo o en parte el legado doctrinal del marxis$\mathrm{mo}^{25}$, se proponen luchar contra el orden (jurídico) establecido, existe una tradición arraigada cuya vitalidad, en los últimos años, se ha visto reflejada en diversas corrientes más o menos originales. El "uso alternativo del Derecho», sobre todo en Italia pero también en España, la «crítica del Derecho» en Francia, los movimientos de "Derecho alternativo» y de «Crítica jurídica» en Latinoamerica, y los «Critical Legal Studies» en los Estados Unidos, aunque con peso también en Europa, son quizás los mejores exponentes de la que, en muchos sentidos, es una nueva filosofía que, como se observa, se caracteriza por su carácter crítico. Crítica frente al iusnaturalismo y el positivismo, frente a la autosuficiencia de la dogmática tradicional, frente a la apoliticidad y la pureza del Derecho y del discurso jurídico, frente a la pretendida coherencia y al carácter completo de los ór-

ciclopedistas, en Francia, el empirismo, el liberalismo y el utilitarismo, en Inglaterra, y en Alemania, Hegel y los hegelianos, con Marx a la cabeza, los que posibilitaron la implantación de la crítica en la sociedad occidental, como nunca antes había ocurrido en ninguna otra sociedad; en T.B. BOTTOMORE, Crítica de la sociedad (trad. por R.A.N. Laporte), Buenos Aires, La Pleyade, 1970 (173 p.), p. 10.

${ }^{24}$ Rudolf STAMMLER, Tratado de Filosofía del Derecho (trad. por W. Roces), Madrid, Reus, 1930 (455 p.), pp. 12-13.

${ }^{25}$ A veces ese legado doctrinal sólo aparece en la lejanía, pues algunos de estos movimientos se encuentran alejados de la tradición de signo marxista. 
denes jurídicos, frente al uso conservador del Derecho ${ }^{26}$. Crítica, en fin, que no oculta la opción ideológica, de izquierdas, que la impulsa.

Si bien en el primer caso, el de los neokantianos, el problema que se planteaba es que optaban por un uso técnico de la palabra crítica, que incluso concebían de manera peculiar, distante del significado que se le otorga en el lenguaje ordinario, ahora los neomarxistas y otros pensadores de izquierdas, si bien utilizan el término de forma más comprensible, plantean otro grave problema. Puesto que, como vimos, la filosofía del Derecho es crítica, y si no lo es, pierde su carácter de auténtica filosofía, entonces resulta que algunos, apropiándose del adjetivo, reducen el todo a la parte: si la filosofía del Derecho es crítica, la filosofía del Derecho es la teoría crítica del Derecho. ¿Significa eso que los otros, acríticos, no pasarían de ser simples ideólogos del Derecho que, por activa o por pasiva, consciente o inconscientemente, sólo tratarían de sostener el orden (jurídico) establecido?

IV.

Una cuestión que surge de inmediato al tratar la del carácter crítico de la filosofía del Derecho, es la de si ese carácter le corresponde también al iusnaturalismo. Ya sabemos que hubo quien defendió que éste no se identificaba, ni siquiera se integraba en los dominios de aquélla y, por tanto, pudiera ser que dado que aquélla es crítica, éste no lo fuera ${ }^{27}$. Sin embargo, es sabido que históricamente el Derecho Natural ha jugado el papel de legitimador o de impugnador del

${ }^{26}$ Vid. Juan A. PÉREZ LLEDÓ, «Teorías críticas del Derecho», cit., p. 100. En parecidos términos, Alan Hunt cuando atribuye a los Critical Legal Studies el rechazo de toda ortodoxia jurídica, del conservadurismo en los estudios de Derecho y del papel que el Derecho juega en las relaciones sociales; en "The Critique of Law: What is "Critical» about Critical Legal Theory?", en Peter Fitzpatrick \& Alan Hunt (eds.), Critical Legal Studies, UK, Basil Blackwell, 1990 (pp. 5-19), p. 5.

27 Fue González Vicén quien en su ya citada y conocida tesis conforme a la cual el concepto de filosofía del Derecho es un concepto histórico, afirmó que realmente la filosofía del Derecho se ocupaba con problemas "gnoseológicos, lógicos y sociológicos», mientras que se desinteresaba de los «ontológicos, metafísicos y éticos»; en «La filosofía del Derecho como concepto histórico», cit., p. 255. De ser esto así, entonces resultaría que la filosofía del Derecho no sería crítica, al menos en el sentido que se le suele dar habitualmente a esa palabra. Pero si, como se reconoce por casi todos, este saber jurídico se caracteriza precisamente por su carácter crítico, entonces tendría razón Pérez Luño cuando advierte que si se le priva de la misión valorativa, es decir, de la labor crítica, la filosofía del Derecho pierde sentido; en Lecciones de Filosofía del Derecho, cit., pp. 109-111. 
status quo y así, incluso si la crítica se reduce a su aspecto censorio, resulta patente que el Derecho Natural es por principio crítico, esto es, que las doctrinas que se agrupan bajo el nomen se ocupan antes que nada de dar criterios para enjuiciar el orden (jurídico) establecido que sea. Por eso conforme a las creencias imperantes sobre el sentido de la filosofía del Derecho, Felipe González Vicén no podía tener razón cuando pretendía que ésta sólo habría de dedicarse «a la teoría de la ciencia, a la lógica, a la sociología», mientras que el Derecho Natural se ocuparía con las cuestiones ontológicas, metafísicas y éticas. ¡Pero si la filosofía del Derecho de la que hablaba no era crítica y, en cambio, al dejar las cuestiones morales en manos del iusnaturalismo, éste sí lo era! Claro que hay que evitar que bajo la capa iusnaturalista se oculten, ideológicamente, los intereses de un grupo o clase, pues tiene razón Xacobe Bastida cuando reconoce que en algunos momentos de su historia el iusnaturalismo jugó un papel crítico, pero en otros se constituyó en ideología sustentadora del poder establecido, llegando a ser «una forma de lo que más tarde se dio en llamar positivismo ético" o ideológico, es decir, santificando lo establecido por el mero hecho de estarlo ${ }^{28}$. Esta última se trata - a mi juicio- de una grave perversión del iusnaturalismo, similar a la del positivismo que quiere hacer pasar al jurista por simple mecánico, técnico neutral o descriptor de lo indescriptible. En este sentido, por más que su nomen no sea el adecuado ${ }^{29}$, el Derecho Natural (no sus deformaciones) puede seguir valiendo como instancia crítica de una razón jurídica que, a imagen y semejanza de la científica, a veces se cree exonerada de rendir cuentas ante el tribunal «de la dignidad humana y las libertades de la persona ${ }^{30}$.

Así las cosas, el iusnaturalismo bien podría contraatacar, pasar a la ofensiva y negarle el pan y la sal al positivismo, al menos a ese positivismo acrítico, ideológico, que dice que la ley es la ley, o que acepta lo que sea por el simple motivo de hallarse establecido. Si la filosofía es ineludiblemente crítica, dirán los partidarios del Derecho Natural, semejante doctrina no es filosofía, o al menos no es una bue-

${ }^{28}$ En El Derecho como creencia, cit., pp. 235-237..

29 En palabras de Gil Cremades, «la inevitabilidad de la pregunta iusfilosófica, si bien no significa una "vuelta al Derecho Natural», sí abre de nuevo el horizonte en que emplazó históricamente el tema «Derecho Natural». No hay un «Derecho Natural» válido siempre y en todo lugar, como tampoco hay una concepción social incriticable, sino que Derecho y sociedad dados han de someterse a la permanente comprobación de en qué medida posibilitan objetivamente la emancipación y la justicia humanas"; en "Un futuro posible de la filosofía del Derecho», cit., pp. 79-80.

30 Vid. Antonio Enrique PÉREZ LUÑO, Lecciones de Filosofía del Derecho, cit., pp. 68,80 y 100 . 
na filosofía, en la medida en que no establece criterios de justicia más allá de la voluntad de quien manda, cuando hoy nadie puede admitir ningún tipo de legítima predestinación al mando ${ }^{31}$. Algo parecido cabría decir - me parece- de quienes aceptan una doctrina relativista ilimitada, pues quien a todo confiere validez, a nada se la otorga: si todo vale, nada vale, con lo cual se niega este positivista a cualquier criterio de enjuiciamiento, precisamente lo que afirman como más importante los partidarios del Derecho Natural. Cuando Kelsen, relativista radical, afirmó que la filosofía del Derecho habría de tener por labor la de elevar una teoría de la justicia ${ }^{32}$, aún no sabemos si estaba bromeando o hablaba en serio, pues el genio ya había defendido desde mucho tiempo atrás que semejante empeño no era posible, al menos con carácter racional ${ }^{33}$.

V.

Pero a la filosofía jurídica no sólo le interesa saber cómo debe ser el Derecho, sino también cómo es de veras, y cómo conocerlo. Éste es otro tópico iusfilosófico absolutamente implantado: junto a la teoría de la justicia habría, por tanto, una teoría del Derecho y otra del conocimiento jurídico, y la crítica entonces bien pudiera darse en estos otros ámbitos ${ }^{34}$. Si se predica del todo, también ha de corresponderle a las partes. El término crítica, empero, se suele utilizar en referencia a la crítica moral y/o política, y a primera vista no se sabe muy bien cómo utilizarla en relación con el concepto del Derecho o con su conocimiento. Si la filosofía del Derecho es crítica, y trata de dar so-

31 «A mi modo de ver - dice Delgado Pinto- lo que de forma más permanente caracteriza al yusnaturalismo radica en su afirmación de que el Derecho no es algo dado como indiscutible por ser imperativo de una voluntad superior o producto de factores histórico-sociales no mediables ni contrastables por la razón humana, sino que constituye un orden de vida social que debe justificarse ante la razón y que ésta puede y debe criticar y, en su caso, mejorar»; en «Los problemas de la filosofía del Derecho en la actualidad», Anales de la Cátedra Francisco Suárez, 1975 (pp. 25-43), p. 26.

${ }^{32}$ Hans KELSEN, Respuesta a la pregunta «Qu'est-ce que la philosphie du droit?», Archives de Philophie du Droit, 1962 (p. 131).

33 Todo juicio de valor -dirá- está «determinado por factores emocionales», lo que trae que sea "subjetivo de por sí, válido únicamente para el sujeto que juzga y, en consecuencia, relativo"; por ejemplo en ¿Qué es justicia? (trad. por A. Calsamiglia), Barcelona, Planeta-Agostini, 1993 (283 p.), p. 39.

${ }^{34}$ Aunque la recojan muchos más, creo que el trabajo tipo que reconoce esa tripartición es el de Norberto BOBBIO, "Naturaleza y función de la filosofía del Derecho", en Contribución a la filosofía del Derecho (trad. por A. Ruiz Miguel), Madrid, Debate, 1990 (pp. 91-101). 
lución a tres grandes problemas, ha de esperarse que sea crítica al referirse a todos, no sólo a alguno de ellos. En el caso de la teoría de la justicia parece claro pues, por principio, es crítica, no tanto en el sentido de que se dedique a criticar este o aquel ordenamiento jurídico, cuanto en el de que elabora los criterios para juzgar este o aquel ordenamiento. Creo que el dato es importante, pero ahora interesan más otras cuestiones. ¿Qué quiere decir que la teoría del Derecho es/debe ser crítica o que lo es/debe ser la teoría de la ciencia jurídica?

En cuanto al carácter crítico de la teoría del Derecho, hay dos posibilidades: o bien sólo son filosóficas las «teorías críticas del Derecho» ("Critical Legal Studies», "uso alternativo del Derecho», etc.), o bien todas lo son, al menos las que sean mínimamente consistentes, esto es, las que ofrezcan razones para el mantenimiento de su postura, con lo que podrán enfrentarse a las otras teorías ${ }^{35}$. La primera opción parece excesivamente estrecha y, salvo a los partidarios de las teorías críticas del Derecho, y tal vez no a todos, a nadie más convencería. La segunda, en cambio, parece más acertada pero implica un uso excesivo, por obvio, del término crítica, que en este caso querría decir fundada, razonable o algo así. Quienes usen la palabra en este sentido, bien pueden ahorrársela, pues no aporta nada a lo que ya se sabe: que en la polémica filosófica hay que ofrecer argumentos. En tanto que ontología, cualquier filosofía jurídica ha de ser crítica, razonable, fundada. La magia, desde luego, no es filosofía.

En cuanto al carácter crítico de la teoría de la ciencia del Derecho, cabría decir algo parecido. En este caso, una teoría crítica de la ciencia jurídica o, mejor, la teoría crítica de la ciencia jurídica, sería sobre todo la que utilizara postulados kantianos, aunque supongo que también los pertenecientes a las corrientes alternativas antes referidas podrían querer reivindicar el término. A la vez, cualquier teoría consistente sobre la Jurisprudencia sería crítica en tanto que aportaría razones para defender sus tesis, y estaría capacitada para

${ }^{35}$ En este sentido, aún parece alejado el día en el que se consiga una unificación de las diversas teorías, lo que sin duda se debe a diversas razones: «Primero, porque no es posible lograr más que una definición excesivamente mínima acerca de algo que no existe universalmente. En segundo lugar, porque una definición es producto del conocimiento [...] y no hay una teoría del conocimiento universalmente aceptada acerca de la corrección de las diversas teorías sobre el Derecho. Finalmente, el Derecho está indisolublemente unido con los valores, tan particulares de cada sociedad como las diversas teorías sobre el Derecho; así que una definición objetiva puede ser o bien el disfraz del valor preferido por el proponente, o bien un esqueleto del fenómeno jurídico que deje de lado el crucial aspecto de los valores»; en Surya PRAKASH SINHA, Why has it not been Posible to Define Law?, Archiv für Rechts-und Sozialphilosophie LXXV/1, 1989 (pp. 1-26), p. 25. 
enfrentarse a las demás. La opción kantiana parece excesivamente estrecha, pero el uso del término con este sesgo epistemológico durante siglos le conferiría cierta validez. La otra posibilidad, de nuevo, nada original añadiría a lo que resulta una evidencia: que cualquier teoría sobre la ciencia jurídica tiene que exponer sus razones frente a las otras, y exigírselas a éstas. En tanto que epistemología, cualquier filosofía del Derecho ha de ser crítica, razonable, fundada. La magia, claro, no es filosofía.

VI.

Entonces, tomado el término en su sentido más obvio, bien se puede decir que la (s) filosofía (s) del Derecho es/son crítica/s, porque no hay una sola, sino muchas y enfrentadas, y todas ellas desarrollan una misma actividad: muestran las contradicciones lógicas de las teorías oponentes y les piden pruebas de lo que afirman, a la vez que agudizan y potencian sus tesis, y buscan demostraciones de las mismas. La etimología de la crítica, entonces, viene al caso, pues lo que hace el crítico es intentar poner en un brete los planteamientos del oponente, tratar de provocar su crisis. Así, las batallas iusfilosóficas resultan productivas: unas doctrinas desaparecen, otras salen reforzadas de la tesitura en que se las coloca.

Además, las teorías filosófico jurídicas tienen, por acción o por omisión, relevancia práctica. Se le otorgue mayor o menor importancia al pensamiento en la construcción de la realidad, no creo que ninguna teoría, por extrema que sea, rechace que tiene alguna. Decir construcción de la realidad implica, por cierto, la realidad política y, en este sentido, la filosofía tiene relevancia política. Ya es clásica la cita de Radbruch: «Si por una parte la Filosofía del Derecho es lucha política de partidos transportada a la esfera del espíritu, puede expresarse, también, por otra, que la lucha política de partidos es una discusión filosófico-jurídica de enorme dimensión. Todas las grandes transformaciones políticas fueron preparadas o acompañadas por la Filosofía del Derecho. Al principio surge la filosofía del Derecho, al final la Revolución ${ }^{36}$. Con Arthur Kaufmann, decir filosofía es decir, y no precisamente en último lugar, "asumir responsabilidades políticas ${ }^{37}$. En el caso de la jurídica, además, con mayor mo-

${ }^{36}$ Gustav RADBRUCH, Filosofía del Derecho (trad. por J. Medina Echevarría), Madrid, Revista de Derecho Privado, 1933 (278 p.), pp. 16-17.

37 Arthur KAUFMANN, «Sentido actual de la filosofía del Derecho» (trad. por A. Ollero), Anales de la Cátredra Francisco Suárez 12 (1), 1972 (pp. 7-36), p. 35. 
tivo, pues el Derecho no es cualquier técnica, sino una técnica propiamente política ${ }^{38}$, con lo que la sola reflexión sobre ella la convierte a su vez en política. Así, tanto se puede hacer filosofía, y política, por acción como por omisión. Quien pretenda abstenerse o ser neutral, también hace filosofía, y política ${ }^{39}$.

Así las cosas, el sentido crítico de la filosofía jurídica también se refiere a su carácter político. Consciente o inconscientemente, subrepticiamente o a las claras, quien hace filosofía hace, aunque no sea en un sentido inmediato ${ }^{40}$, política y entonces es crítica, porque toda política es crítica frente a otra política distinta. Ahora bien, se debe subrayar que esto no significa que toda filosofía sea progresista, término con el que muchas veces se identifica el otro. Crítica quiere decir que otorga criterios, y éstos tanto pueden ser de uno como de otro signo. La filosofía del Derecho, por tanto, sería una racionalización del debate y la práctica política.

\section{VII.}

Pero el problema principal que plantea reivindicar el carácter crítico para la filosofía del Derecho es que pudiera entenderse que la crítica es una nota monopolizada por este tipo de conocimiento, de tal manera que los otros saberes sobre el Derecho, y sobre todo el de la ciencia jurídica, no son/habrían de ser críticos. Me parece que la aporía del monopolio iusfilosófico de la crítica la planteó en sus justos términos García Amado, quien curiosamente no afirma que el carácter crítico sea distintivo de la filosofía ${ }^{41}$ : "asumir para la filosofía

38 Juan Ramón CAPELLA, "La crisis actual de la enseñanza del Derecho en España", en Juan José Gil Cremades (dir.), La enseñanza del Derecho. Seminario de profesores de la Facultad de Derecho, Zaragoza, Institución Fernando el Católico, 1985 (pp. 23-42), p. 24.

39 Ningún jurista, ninguno, puede dejar de tomar una «opción metajurídica». Sencillamente, "no tiene libertad de no hacer» filosofía, ni política: vid. Jean-Louis GARDIES, Respuesta a la pregunta «Qu'est-ce que la philosophie du droit?, en $A r-$ chives de Philosophie du Droit, 1962 (pp. 118-120), p. 118. Las palabras de Ollero serán clarificadoras: «todo jurista es inevitablemente político y asume una responsabilidad ética, porque su labor de conocimiento no aparece ahora como un soliloquio aséptico, sino como una conformación del mundo en el que él y sus semejantes están [...] Todo conocimiento del Derecho es un crear Derecho. Toda ciencia jurídica es política jurídica. La frontera entre ser y deber ser tiene límites movedizos e históricos»; en Andrés OLLERO, "Una filosofía jurídica posible», Anales de la Cátedra Francisco Suárez, 1975 (pp. 247-278), p. 263.

40 Vid. José DELGADO PINTO, «Los problemas de la filosofía del Derecho en la actualidad", cit., p. 42.

41 Tampoco Manuel Atienza, quien ya vimos que reivindicaba el carácter crítico de 
del Derecho el papel de la crítica, frente a una dogmática supuestamente acrítica, no es cuestionar el modelo «oficial» de enseñanza y práctica del Derecho, sino sancionarlo, darlo por bueno o definitivo» ${ }^{42}$. Eso sí, si crítico es lo contrario de dogmático, los defensores del modelo «oficial» habrían sabido encontrar para la dogmática el nomen más adecuado, que mostraría el carácter ideológico, acrítico y acientífico, de ésta ${ }^{43}$. Empero, ¿no es la jurisprudencia una ciencia, aun social? ¿Y no se habla de economía crítica, sociología crítica, historia crítica, pedagogía crítica? ¿Acaso no son críticas las ciencias sociales $^{44}$ ? Entonces, como en su momento se preguntaron Laporta, Hierro y Zapatero, ¿por qué «confiar la crítica a un gremio de sacerdotes con patente de proclama de lo justo y de lo injusto? ${ }^{45}$.

Las ciencias sociales - me parece-, también el Derecho, son críticas en dos sentidos: en tanto que ciencias y en tanto que sociales. En tanto que ciencias, pues el científico es el más crítico de todos los procedimientos del saber. En el ámbito de la ciencia, nada se da por sentado; cada nueva teoría ha de ser sometida a contrastación, criticada y, además, constantemente. Creo que es en este sentido en el que se puede decir que la ciencia no ha de ser dogmática, pues en otro caso, es decir, si se aceptan sin más ciertas verdades, no hay ciencia. Sin duda las humanas o sociales se encuentran aún lejos del

la filosofía del Derecho. Frente a la dogmática tradicional, empero, el mismo carácter predica de la ciencia jurídica. Refiriéndose a la enseñanza del Derecho, dice: «Lo que caracteriza [...] a nuestras Facultades jurídicas es que, probablemente, lo que se enseña en ellas no merece, en general, el nombre de ciencia. Las conexiones de la "ciencia» jurídica con la teología (tantas veces señaladas) son bastante claras y, desde luego, es todo un síntoma (un mal síntoma) la existencia de unos «científicos» que no dudan en calificar de «dogmática» su actividad»; en "¿Es posible una enseñanza científica del Derecho?, Revista de la Facultad de Derecho de la Universidad Complutense de Madrid 54, verano de 1978 (pp. 109-113), pp. 109-110.

42 Juan Antonio GARCÍA AMADO, "Algunas consideraciones sobre la filosofía del Derecho y su posible sentido actual», Anuario de Filosofía del Derecho VII, 1990 (pp. 261-280), p. 275.

${ }^{43}$ Con referencia a la educación jurídica, lastrada por una concreta concepción de la ciencia del Derecho, lo expresa bien Francisco J. Laporta: «El centro de nuestra más generalizada pedagogía del Derecho es la contemplación descriptiva y acrítica de ese texto legal, mudo y muerto, de la misma forma que en la teología exegética el texto bíblico marca por definición los límites de la materia»; en "Notas sobre el estudio y la enseñanza del Derecho», Sistema 24-25, junio de 1978 (pp. 107-112), p. 108.

44 Ya está apuntado el relevante papel que jugaron las nuevas ciencias sociales en el movimiento de implantación de la crítica: vid. T.B. BOTTOMORE, Crítica de la sociedad, cit., p. 14.

45 Entre otras razones, vendrán a decir, porque parece que el jurista, un especialista por principio, no podría elevar una «conceptualización totalizadora-crítica del fenómeno jurídico"; en "Algunas observaciones sobre la situación de la filosofía del Derecho en la actualidad», cit., p. 119. 
paradigma de las naturales, más precisas, pero si pueden ser llamadas ciencias es porque, en sus territorios, es posible dudar de cualquier afirmación, poner a prueba cualquier pretensión. En el caso de la Jurisprudencia, una interpretación doctrinal con pretensiones de cientificidad ha de ser expuesta ante la comunidad de los científicos del Derecho, y quienes la integran están legitimados para pedir explicaciones. Al fin, serán los criterios de corrección que se manejen los que hagan que se acepte o se deseche la nueva tesis. Por supuesto que casi siempre puede haber tesis en pugna, equilibradas todas ellas por razones de tanto peso que resulte poco menos que imposible descartar alguna de ellas. Aun así, la existencia de varias posibles, implica que hay otras insostenibles.

Pero las ciencias sociales también son críticas en tanto que sociales. Es cierto que el positivismo proclamó la posibilidad de las ciencias humanas dado que también en éstas, como en las naturales, podría existir una distancia suficiente entre el sujeto y el objeto. Un sujeto cognoscente que, separado de su objeto de conocimiento, podría estudiarlo objetivamente, ajeno por tanto a los influjos de su propia conciencia moral. El sociólogo, el etnólogo, el historiador, no habrían de juzgar la sociedad o la historia que investigaban, sino sólo describirla. Hoy, el primer problema que se les planteó nos resulta obvio: ¿por qué describir esto y no aquello? Amén de que ese cometido nos pueda parecer insuficiente, la sola narración de ciertos datos y la omisión de otros ya reflejaba el criterio valorativo del científico. Pero aún hay más, y más grave: "La prohibición de juicios de valor en las ciencias sociales nos traería como consecuencia el permiso de describir en modo estrictamente fáctico las acciones visibles que pueden observarse en un campo de concentración y de analizar de modo igualmente fáctico las motivaciones de los agentes involucrados, pero prohibiéndonos hablar de crueldad. Cualquier otro lector no enteramente idiota de una tal descripción se daría desde luego cuenta de que las acciones descritas son crueles. La descripción fáctica sería en realidad una sátira amarga. Lo que pretendía ser relato escueto sería un relato inusitadamente censurado. Su autor estaría suprimiendo adrede lo que sabe y [...] se estaría haciendo culpable de deshonestidad intelectual [...] todo el procedimiento nos recuerda un juego infantil en que el que pierde es el que pronuncia ciertas palabras que sus compañeros de juego continuamente lo impelen a pronunciar [...] Poner las palabras pertinentes entre comillas es un truco pueril que da la posibilidad de hablar de cosas importantes negando al mismo tiempo los principios sin los que no puede haber cosas importantes. Un tru- 
co que permita unir las ventajas del sentido común con la negación del sentido común» ${ }^{46}$.

A la jurisprudencia podríamos imaginarla en una situación semejante. Al fin y al cabo, también el nacional-socialismo contó con sus juristas dedicados a describir e interpretar el orden jurídico nazi. $¿$ Ese Derecho, como el campo de exterminio, podría ser descrito objetivamente, sin rastro de juicios de valor? También en este caso quien así actuara estaría representando una sátira amarga. Pero si las ciencias, también las jurídicas, critican, necesitan criterios, y en este sentido no son autosuficientes pues no son ellas los que los elaboran. La labor competería a la filosofía del Derecho, que se dedica a proponer criterios consistentes, tanto de corrección como de justicia. De corrección, ya que la filosofía de la ciencia, también de la jurídica, eleva pautas que avalen la consistencia de la tesis mantenida, se dedique ésta a explicar o a interpretar. De justicia, ya que la teoría de la justicia se ocupa precisamente con la elaboración de criterios que puedan utilizarse para someter a juicio una situación, teoría o norma.

\section{VIII.}

Aunque sea breve, hay que abrir una nueva sección para apuntar otra labor de la Filosofía del Derecho que tiene que ver con la crítica, la de enseñar a criticar. Ésta sería la gran justificación que las asignaturas de este corte tendrían en la enseñanza del Derecho. Desde Sacristán hasta García Amado, así ha sido reconocido ${ }^{47}$. Pero ahora, en este punto, no quiero acumular citas; baste con destacar el muy importante artículo que Pérez Lledó ha dedicado a la enseñanza del Derecho, precisamente por que - a su juicio - ésta ha de tener una finalidad cognoscitiva, práctica y crítica, entendiendo por esta última la «educación en fines y valores». Es cierto que la labor de enseñar a

46 La cita pertenece a Leo Strauss, y la tomo de José Porfirio MIRANDA, Apelo a la razón. Teoría de la ciencia y crítica del positivismo, Salamanca, Sígueme, 1988 (508 p.), p. 131. Y continúa ahora Miranda en la misma página: "El positivismo no ha caído en la cuenta de que, ante la realidad de un campo nazi de exterminio, las proposiciones que usan la palabra "inicuo» son proposiciones básicas con tantos derechos gnoseológicos y ontológicos como las proposiciones que expresen número y edad y sexo de los prisioneros. En ambas por igual se trata de interpretaciones de la realidad, producidas por nuestro aparato cognitivo».

47 Manuel SACRISTÁN, «Sobre el lugar de la filosofía en los estudios superiores», cit., p. 372; Juan Antonio GARCÍA AMADO, «Algunas consideraciones sobre la filosofía del Derecho y su posible sentido actual», cit., p. 275. 
criticar no ha de quedar sólo en manos de los filósofos del Derecho - viene a decir-, pero también que éstos parece que han de estar especialmente interesados en ella, pues el problema de la justificación de los valores morales, fundamental para desarrollar con rigor la labor crítica, "ha de ser introducido, típicamente, en asignaturas encomendadas a los filósofos del Derecho». Por supuesto que a los científicos del Derecho también les corresponde esta misión: "no hace falta ser un filósofo moral profesional, ni haber abrazado una "gran teoría» moral, dominando su contenido, para poder practicar una enseñanza orientada por valores morales y argumentando a su favor ${ }^{48}$. No sólo los filósofos del Derecho - diríamos-, pero también y sobre todo ellos han de dedicarse a enseñar cómo criticar o, al menos, a enseñar cosas que tienen mucho que ver con cómo criticar.

IX.

Pero dejemos ahora la cuestión del papel de la crítica en la enseñanza del Derecho y concluyamos. La conclusión de este trabajo debe sistematizar los diversos usos que se le otorgan al término critica por los filósofos del Derecho, así como someter a crítica la tesis que afirma que la filosofía del Derecho es/debe ser crítica. A mi juicio, hay cuatro posibles usos de la palabra en relación con este tipo de conocimiento.

a) Un uso primero que no debe dejar de apuntarse es el que le dan quienes, por motivos retóricos, estéticos, se declaran críticos y afirman que la filosofía del Derecho es crítica. Así su significado es, en muchos casos, intrascendente. Es el mismo uso - creo- que se encuentra cuando se oye decir que el intelectual, para serlo de veras, ha de ser crítico, sin especificar nada más. La palabra, como ocurrió con otras (pienso en dialéctica o estructura, tan de moda en su momento), serviría para conseguir un empaque que ocultaría la vacuidad del discurso. La crítica, en fin, como pose.

b) Otro uso del término, aunque creo que hoy poco frecuente, es el que lo vincula con la tradición del kantismo. En este caso, la filosofía del Derecho sería crítica en tanto se dedicara a aclarar las posibilidades y los límites del conocimiento jurídico. Se tra-

48 Juan Antonio PÉREZ LLEDó, «Teoría y práctica en la enseñanza del Derecho», Anuario de la Facultad de Derecho de la Universidad Autónoma de Madrid 6, 2002 (pp. 197-268), pp. 213 y 260-261. 
taría de una utilización alejada de la del lenguaje ordinario y, por tanto, en muchos casos, exigiría aclaración. Por supuesto, nada impide que sin ser kantiano, un filósofo del Derecho admita este sentido epistemológico.

c) El uso vulgar del término, aun dentro de los marcos de este tipo de conocimiento, no tiene por qué ser desacertado. En su genérico significado de juicio, que la filosofía jurídica es crítica denota que juzga las diversas concepciones del Derecho, de la ciencia jurídica y de la justicia. Esto muestra otra cuestión relevante a veces olvidada, que no es la filosofía del Derecho sino las diversas filosofías del Derecho las que son críticas, y lo son entre ellas, pues lo que tratan de hacer es que las otras entren en crisis. Una filosofía acrítica, que no juzga las doctrinas contrincantes y se ocupa con asuntos que a nadie interesan, no es filosofía. La filosofía del Derecho es una tradición que incluye la lucha ideológica. Tal vez por esta razón, el término analizado suele utilizarse en referencia a la teoría de la justicia, más que a la del Derecho y a la de la ciencia jurídica.

d) Un uso más restringido se refiere al carácter político de este saber, toma el término en su acepción de censura o condena, y se decide por una alternativa revolucionaria, subversiva o, sencillamente, transformadora. Aunque haya habido otros, no es extraño que hayan sido los marxistas quienes más resaltaran este significado. Lo que sí conviene apuntar a este respecto es que a veces, sin decirlo expresamente, niegan la consideración de filosóficas a las concepciones del Derecho y de la justicia de sus contrincantes políticos. Si la filosofía del Derecho es crítica, esto es, transformadora, la que tenga un cariz conservador, no es filosofía del Derecho. Supongo que no pasaría de ser más que ideología. Sin embargo no es serio pretender que Hobbes, por ejemplo, no hizo filosofía del Derecho. Más que insultar subrepticiamente a sus adversarios, lo mejor sería volver a la acepción anterior y debatir con ellos sus planteamientos.

Así las cosas, tengo para mí que el significado que más nos interesa de la crítica iusfilosófica es el de examen y juicio. Por supuesto que del juicio se puede seguir una condena, pero ya vimos que en la argumentación filosófica, como en la procesal en general, se deben seguir las correspondientes reglas procesales: quien acusa está obligado a probar, y quien es acusado tiene derecho a la defensa. También el proceso filosófico tiene su Derecho. En ese sentido la filosofía, 
como la ciencia y cualquier otro conocimiento que se tenga por racional, es crítica en tanto que sus resultados están sometidos al juicio de una comunidad intelectual: quien proponga una tesis nueva o refute otra ya establecida, ha de presentar la original o la acusación, con sus fundamentos, ante un tribunal juzgador, el formado por el resto de la colectividad dedicada a la filosofía jurídica. Esto ha de ser así, por cierto, salvo que queramos convertir el conocimiento filosófico en algún tipo de saber esotérico o místico, ante el que no haya nada que decir ni que juzgar. En este sentido, sin embargo, la utilización del término no aporta gran cosa, pues casi todos los que se dedican a la filosofía del Derecho reconocerán que quien afirma una tesis ha de probarla, esto es, de fundamentarla. En otros términos, que la filosofía no es dogmática, dado que no puede afirmar nada "porque sí».

Pero la filosofía del Derecho no sólo es crítica en el sentido visto. Por extensión, hay otro uso de la expresión que, aunque no se sigue de su literalidad, es correcto; tanto, que sugeriré que esto es lo que se quiere decir habitualmente cuando se dice que la filosofía jurídica tiene un carácter crítico, o cumple una función crítica, o tiene un sentido crítico, o algo semejante. Aunque se ocupe con la organización de la sociedad, la reflexión que normalmente se denomina filosófico jurídica, no suele ser crítica como lo es la actividad política, por mucho que se insista en que aquella reflexión no se dedica a describir el Derecho, lo que correspondería a la ciencia jurídica, sino a juzgarlo. Esta afirmación es - creo- errónea. La filosofía del Derecho ni se dedica, ni debe dedicarse, a criticar un concreto Derecho positivo. Es cierto que los filósofos académicos del Derecho, a veces, pueden lanzar sus críticas sobre una determinada normativa o sobre un Derecho que, por ejemplo, vulnera el principio conforme al cual debe proteger los derechos humanos. Claro que censuras de este tipo pueden ser hechas igualmente por otras personas, sin que esto haya de plantear mayores problemas. Es más, creo que los más competentes para llevar a cabo la crítica del Derecho son precisamente los científicos del Derecho. Guste o no, los filósofos del Derecho no suelen ser especialistas en Derecho positivo, al menos en nuestro país, porque también es cierto que en otros la especialidad exige combinar una rama de la ciencia jurídica con la filosofía del Derecho. Al menos en nuestro país, por tanto, quienes están capacitados para la crítica son los científicos del Derecho, pues ésta exige un conocimiento a fondo del objeto de la posible crítica, así como criterios para llevar a cabo la labor. El objeto coincide con el de su disciplina y, entonces, nadie mejor que ellos para juzgar con conoci- 
miento de causa. Faltan los criterios, y éstos son los que les proporcionan los filósofos del Derecho, quienes se dedican a elaborarlos, a construirlos. Quienes se ocupan con las por lo demás fundamentales cuestiones de la teoría de la justicia, cuestiones que, razonablemente, se suele identificar con el ámbito de la crítica, son los filósofos del Derecho (aunque también los de la moral y los de la política), que tienen entre sus cometidos el de apuntar criterios de justicia, pues aquélla realmente es la teoría de los criterios de la justicia. En este sentido, los filósofos del Derecho son críticos no porque profesen una u otra filosofía, sino porque construyen criterios de justicia. Habitualmente se dice de alguien que es un crítico (literario, artístico, etc.) por juzgar, conforme a ciertas pautas, un objeto (literario, artístico, etc.). En cambio, quienes elaboran las pautas son los teóricos (de la literatura, del arte, etc.). En el caso del Derecho, los que deben juzgar son los científicos, mientras que los filósofos deben trabajar en la elaboración de las pautas del juicio.

Si el filósofo del Derecho es crítico, lo es no porque critique, lo que carecería de sentido (o tendría el mismo que en el caso de cualquier otra persona no especialista en el Derecho positivo), sino porque elabora y afila los criterios que pondrá en manos de científicos y políticos. En general, su labor es la de comprender el mundo (jurídico) y posibilitar su crítica o, lo que es lo mismo, su mejora. Que se sepa, eso sí, que ni todo es criticable, ni vale lo mismo un criterio que otro. Al fin, el de crítico es un oficio moral. 